Language and Cognition 13 (2021), 613-642. doi:10.1017/langcog.2021.15

(C) The Author(s), 2021. Published by Cambridge University Press. This is an Open Access article, distributed under the terms of the Creative Commons Attribution licence (http:// creativecommons.org/licenses/by/4.0/), which permits unrestricted re-use, distribution, and reproduction in any medium, provided the original work is properly cited.

\title{
Yoga instructions in Polish and Russian as directive speech acts: a cognitive linguistic perspective
}

\author{
IWONA GÓRALCZYK*
}

\author{
A N D \\ JOANNA ŁOZIŃSKA \\ University of Warmia and Mazury in Olsztyn, Poland \\ (Received 13 Fuly 2020 - Revised 28 fune 2021 - Accepted 28 fune 2021 - \\ First published online 17 September 2021)
}

\section{A B S T R A C T}

This paper offers an account of within- and between-language differences in the grammatical encoding of directive meaning as represented in yoga discourse in two cognate languages: Polish and Russian. Specifically, the focus is put on three constructions: the imperative and the imperfective non-past indicative in both languages, and the indicative past, which is utilised only in Russian. In the analysis, we make an eclectic selection of methodological tools, drawing on a few models of illocution which have been put forward within Cognitive Linguistics. As is shown, even if yoga instructions are generally assessed as relatively weak directives, there are fine-grained differences in some aspects of construal evoked by the examined constructions resulting in differences in the force impact among the respective patterns and in their distribution. In the analysis, we consider such aspects of construal as: (i) the actuality or virtuality of the event presented in the utterance; (ii) the presence or absence of the speaker in the onstage region; and (iii) the aspectual opposition between an ongoing or completed event. The analysis, which is both qualitative and quantitative, has been based on a corpus of 300 randomly selected instructions in each language (600 in total).

KE Y W O R D : directive speech act, force impact, Polish, Russian, yoga discourse

[*] Address for correspondence: e-mail: iwona.goralczyk@uwm.edu.pl; joanna.lozinska@uwm. edu.pl 


\section{Introduction}

The present analysis is a data-driven study of clausal constructions associated with the illocutionary meaning of an instruction, in both direct and indirect directive speech acts, in the discourse of yoga in Polish and Russian. ${ }^{1}$ Specifically, we attempt to investigate three syntactic patterns attested in the data collected from the yoga recordings that we examined: two sentence types used in both Polish and Russian, i.e., imperative clauses, as in (1-2), and declaratives instantiated by imperfective non-past verbs in the indicative mood, as in (3-4); and one construction which has been attested solely for Russian, in which the verb in the declarative clause type is in the indicative past form, as in (5): ${ }^{2}$

$\begin{array}{lll}\text { Spleć } & \text { palce } & \text { dłoni. [Pl] } \\ \text { interlace-2SG-IMP-PFV } & \text { fingers-ACC.PL } & \text { hand -GEN.SG } \\ \text { interlace your fingers } & & \end{array}$

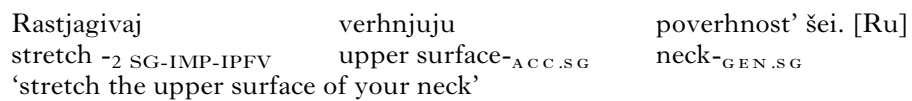
Znów odkręcamy
again turn-1PL-IND (NON-PAST)-IPFV Wrists-Ac C PL
'we turn the wrists again'

\begin{tabular}{|c|c|c|c|}
\hline $\begin{array}{l}\text { Dyšim } \\
\text { breathe-1PL-IND (NON-PAST)-I P F V }\end{array}$ & $\begin{array}{l}\text { Životom } \\
\text { belly -IN S T R.SG }\end{array}$ & $\begin{array}{l}\text { čerez } \\
\text { through }\end{array}$ & $\begin{array}{l}\text { nos. }[\mathrm{Ru}] \\
\text { nose-Acc.PL }\end{array}$ \\
\hline
\end{tabular}

[1] We would like to thank the anonymous reviewers for providing invaluable feedback which shaped the final version of this paper. Needless to say, any shortcomings of the text are our own responsibility.

[2] The grammatical systems of Polish and Russian distinguish only between two tenses: past and non-past (cf. Grenoble, 1989; Kochańska, 2002, p. 352; for the sake of the present analysis we disregard the imperfective periphrastic future byt' plus the infinitive; cf. Grenoble, 1995; Kochańska 2002, p. 353). As will be shown in the paper, directive utterances, which by their very nature pertain to actions which are future relative to the speech event, employ the full range - past and non-past tenses - in Russian and the non-past tense in Polish, when they are expressed in the indicative mood. In non-past indicatives, further meaning distinctions arise in the interaction of non-past tense and imperfective and perfective aspect. In both Polish and Russian, the imperfective non-past indicative construction prototypically involves the present-time meaning, while the prototypical interpretation of the perfective is that of futurity (Grenoble, 1989, p. 98, 1995, p. 186; Kochańska, 2002, p. 353). However, in both Polish and Russian, the imperfective has also extended uses in which it is employed to refer to future-time occurrences. It is precisely the extended use of the imperfective construction in both languages that is relevant for the present analysis. 


$$
\begin{array}{llll}
\begin{array}{l}
\text { Na vdohe } \\
\text { on inhale }
\end{array} & \text { vstali } & \text { na } & \text { noski. }[\mathrm{Ru}]^{3} \\
\text { stood-1 } 1 \text { PL-IND (PAsT)-PF v } & \text { on } & \text { toes-Acc.PL }
\end{array}
$$

'on the inhale we stood on the toes'

In selecting an interface between illocutionary meaning and its grammatical encoding as an area of investigation we follow a long-standing interest among linguists of many theoretical persuasions, and particularly the rich tradition of cognitive linguistic research (e.g., Croft, 1994; Kochańska, 2002, 2011, 2015, 2018; König \& Siemund, 2007; Levinson, 1983; Panther \& Thornburg, 1998, 2003; Pérez Hernández \& Ruiz de Mendoza, 2002; Ruiz de Mendoza \& Baicchi, 2007; Siemund, 2018; Thornburg \& Panther, 1997). Adding a focus on the between-language differences, we set out to investigate language-specific preferences in the selection of the above-mentioned grammatical constructions to code a directive speech act in a rarely studied discourse genre and in a very special social context. In yoga, the contextual circumstances of the speaker-hearer interaction, as well as the interactive behavioral effects of the directive constructions, are identical in both languages, while the constructions are semantically comparable in many respects. All these communicative parameters being equal, there are astonishing contrasts in the preferred grammatical patterns of yoga instructions which we have observed in the corpus for Polish and Russian that we created for the sake of the present analysis. The selection of the languages has been motivated by the fact that Polish and Russian are genetically related and have for centuries remained in contact, which has given us an opportunity to compare languages that have striking typological similarities.

The goal of the present analysis is, broadly, threefold. Firstly, we shall present a quantitative analysis of the distribution patterns of the respective clause types in the corpus of 300 clausal tokens for each language (600 tokens in total). Here, we shall be paying direct attention to the between-language differences in the distribution of the examined constructions. Secondly, assuming that the observed contrasts can at least partly be attributed to the inherent nature of the constructions themselves, we shall narrow down the focus and present some qualitative investigations individually into each construction. Thirdly, following some research on ecological motivation in grammar (Radden, 2014; Radden \& Dirven, 2007, pp. 4-5; Radden \& Panther, 2004, pp. 24-26) and acknowledging the claim that the examined constructions - employed in each language to convey apparently comparable meanings in a

[3] The past tense inflection on the verb in Russian makes no formal distinction between first, second, and third person in the plural. In contrast to the statement use, the directive use of the construction makes a semanto-pragmatic distinction between the speaker-inclusive 1P L and the speaker-exclusive 2PL. For reasons which will be explained in Section 5.3., we assume that all the past-tense instances with an unexpressed subject are cases of the speakerinclusive $1 \mathrm{PL}$. Such a grammatical specification is thus put in the gloss. 


\section{GÓRALCZYK AND ŁOZIŃSKA}

similar context of use and thus specialised for different 'jobs' - should not be viewed in isolation, we shall provide their integrated account in the studied discourse genre in each language. Drawing on the typological similarity of Polish and Russian, we further compare and contrast the constructions in both languages, aiming to explicitly elucidate the nature of the differences which underlie the between-language selection preferences attested in our corpus.

\section{Previous research on illocutionary function - grammatical form relation: an overview}

Broadly, studies on illocution have focused on an interplay between the precise nature of the illocutionary meaning of an utterance, the lexical and grammatical import of the linguistic pattern conveying the illocutionary meaning, and finally the role of contextual factors in the construction and interpretation of the utterance as a speech act. In some early pragmatic research illocution was given inferential accounts, according to which, speech acts, both direct and indirect, were interpreted through fully context-dependent inferential activity, or due to reinterpretations of sentence meaning based on salient contextual information, with no clear connection to the grammatical form employed to encode them (e.g., Bach \& Harnish, 1979). Alongside an inferential approach there were also early observations that particular kinds of illocutionary acts correlate with the employment of particular kinds of linguistic structures. In some such research illocutionary meaning was classified only broadly, for example, as stating or asserting, questioning, commanding, and exclaiming, following its grammatical encoding as, respectively, declaratives, interrogatives, imperatives, and exclamatives. Other accounts offered some more fine-grained divisions of speech acts. For illustration, Austin's classification comprised verdictives, exercitives, commissives, behabitives, and expositives, which were correlated to the use of specific performative verbs such as, respectively: acquit, appoint, bet, apologise, answer, etc. (1962, p. 149). Sentence types and performative verbs in the above-mentioned classifications belong to illocutionary force indicating devices (IFIDs), which have been posited in the literature to define the kind of illocutionary force of an utterance. An attempt to identify the illocutionary force of an utterance with an aspect of sentence meaning used in that utterance led in the 1970 s to the Performative Hypothesis, according to which all utterances are performative and each includes a compositionally derivable formula including a performative verb: I hereby state/request, etc. (Siemund, 2018, pp. 351-354).

Another approach to the classification of illocutionary acts is proposed by Searle (1976). His famous typology of speech acts, whereby a distinction is made among representatives, commissives, declarations, directives, and expressives, is underlyingly guided by 'conceptual' criteria. These include as the central ones: (i) the illocutionary point (purpose) of the act; (ii) the direction of fit between the 
words and the world; and (iii) the speaker's attitude or the expressed psychological state (1976, pp. 2-7). However, it has to be noted that, even if his classification makes no direct recourse to the linguistic encoding of a given illocutionary act, Searle's approach to the problem of the relationship between the lexicogrammatical make-up of an utterance and its illocutionary force has been very much shaped by his principle of expressibility ("whatever can be meant, can be said” 1969, p. 20). It should also be noted that in his (1969) work Searle was quite sympathetic to the idea developed within the Performative Hypothesis.

More recent descriptions tend to focus on the grammatical parameters of speech acts. For illustration, König and Siemund (2007) link the declarative clause type in the default functions with asserting, claiming, and stating, but also with accusing, criticising, guaranteeing, promising, and performative acts; and they link the imperative with a range of speech act meanings, such as suggestions, prescriptions, appeals, exhortations, etc., to mention the grammatical constructions relevant for this analysis. In König and Siemund's model, whereby a typological perspective is assumed, a sentence type should be thought of as the communicative potential, and the specific illocutionary act as an effect of an interaction between this potential, contextual factors, and also partly cooperative negotiations between the speaker and the hearer (2007, pp. 276-277).

The current cognitive linguistic approach to speech acts fully endorses the claim that the role of contextual factors in the interpretation of illocutionary meanings is pivotal, alongside some more schematic aspects of illocution. According to Langacker, the illocutionary force of an utterance always remains implicit, and bringing it to the fore, as well as interpreting its actual nature, lies with the hearer, who uses all the available clues, including the contextual ones (e.g., 1998, pp. 652-656).

Furthermore, Langacker's model of language is usage-based, which means that the speaker's understanding of a speech act, or any other linguistic knowledge of the speaker, resides in networks of cognitive models, which are all schematisations over recurrent aspects of human social interactions. They all contribute to a generalised schematic interactive frame which underlies a clause uttered with a particular illocutionary force in a more or less prototypical variant of a speech act (e.g., Langacker, 1998, p. 653; see also Kochańska, 2011, pp. 181-183). The models relevant to directives, for example, capture our understanding of obligations, rights, needs, morality, social power, interpersonal goals pertaining to exerting influence, etc. The models also include our experience related to the range of applications and strength of imposition patterns, among other factors (Kochańska, 2018, p. 4). In a specific instance of use, when a given grammatical structure is selected by the speaker to convey the intended illocutionary meaning, the relation between speech event participants - which is conventionally, or virtually, associated with this structure - becomes an actual relation. Aspects of the virtual relation are put in 


\section{GÓRALCZYK AND ŁOZIŃSKA}

correspondence with the actual interactive and interpersonal context as it is understood by the speaker and the hearer (e.g., Langacker, 2004, pp. 545-552, 2009, pp. 153-158; Kochańska, 2018, p. 4).

A more generic component of the interactive frame in the above model is claimed to operate on a conventional conceptual Gestalt of an illocutionary scenario. In brief, the structure of the scenario consists of four stages: the BEFORE, relating to necessary preconditions for the scenario to get evoked, such as motivations, potentialities, capabilities, abilities, dispositions, etc.; the C O RE , pertaining to the constitutive aspects of a given scenario; the E F F E C T S / RESULT, relating to the consequences immediately following from the scenario; and the A F T E R, which pertains to the non-necessary consequences of the scenario (Panther \& Thornburg, 1999, p. 337). The scenario is elaborated into a finer-detail model in a specific speech act. Furthermore, underlying and supporting the inferential schemas that operate on the scenario, there are some cognitive operations such as metonymic mappings, which provide mental shortcuts facilitating intended interpretations (Panther \& Thornburg, 1998, 2003; Pérez Hernández \& Ruiz de Mendoza, 2002; Ruiz de Mendoza, 2014; Ruiz de Mendoza \& Baicchi, 2007; Thornburg \& Panther, 1997). Specifically, each component of the scenario, for example, the B E F O R E stage, can provide mental access to the whole. For example, the question about somebody's physical ability to perform an activity, such as Can you reach the salt?, is conventionally identified as part of the scenario and is naturally followed by another part, i.e., a perlocutionary effect. The role of the context in a specific usage event is not diminished in this model - Panther and Thornburg formulate a hypothesis that the more components of a particular speech act scenario that are present in a given context of use, the more likely it is that "even a relatively peripheral component can stand metonymically for the [relevant] scenario" (1998, p. 768). Panther and Thornburg's model shall prove to be of particular relevance for this study. As will be demonstrated, an illocutionary scenario underlies language users' inferential activity in identifying the utterances that employ the non-past and past tenses as instructions for the immediate future.

Finally, illocutionary force in speech acts has widely been accounted for in terms of some specific culture-bound regulations in social behavior. These include such factors as the relative authority, or power, of the speaker and hearer, the relative costs and benefits of the relevant activity to each, and the requirement of compliance or optionality to perform this activity (e.g., Pérez Hernández \& Ruiz de Mendoza, 2011; Ruiz de Mendoza 2014, p. 158; Takahashi, 2012).

\section{Hypotheses, data, and method}

Drawing on some of the research into the interface between the illocutionary function of an utterance and the grammatical form employed to convey the 
illocutionary meaning, which has been overviewed in the preceding section, and especially inspired by the widely accepted illocutionary scenario account, we shall advance the first hypothesis that, given that the scenario can be employed in a variety of ways (facilitated by the cognitive operation of metonymy), there will be more than one construction within the system of each studied language conventionally employed to convey directive meaning in the same discourse context and bringing about a similar perlocutionary effect (Hypothesis 1).

Additionally, given typological studies such as König and Siemund (2007) and Siemund (2018), according to which language systems differ in the possible range of constructions which are used to convey illocutionary meanings, we hypothesise that the sister languages studied, Polish and Russian, differ to some extent in the types of constructions used for expressing yoga instructions. As a consequence, there will also be statistically significant quantitative differences between the two languages in the distribution patterns of the studied constructions (Hypothesis 2). This hypothesis is based on quantitative research and we shall start the results section with the analysis thereof.

Finally, based on some research on ecological motivation in grammar, we hypothesise that the examined constructions differ relative to each other / one another within each language, and that each construction has a slightly different semantic value (Hypothesis 3). The qualitative analysis of the attested constructions will be provided in the discussion section of this research.

To begin with, however, let us briefly describe the interactive circumstances in which the examined constructions are used in the situational context of a yoga class. The environment of the speech situation underlying the use of a yoga instruction is identical for the speakers of both Polish and Russian. Technically, yoga is not a sport and it is not competitive. It is meant to bring to the practitioner physical and mental well-being. The yoga instructor is a professional, semi-institutionalised authority with special training. The instructor and the practitioners are typically neither strangers nor intimates to each other and to one another. It is an essential characteristic of the interactive circumstances in a yoga class that the atmosphere is relaxed and friendly and that, crucially, full distance between the interlocutors is not maintained. Typically, the yoga instructor presents a yoga posture, called asana, to the practitioners, who imitate it. It is a default arrangement that the hearer is naturally willing to follow the instruction as the action is performed for their own good. In such specific interactive circumstances, utterances like (1-5) produce a non-linguistic, behavioural response, i.e., a more dynamic or a less dynamic, self-controllable action, which takes place in the immediate future relative to the moment of speaking. Put differently, independent of the underlying clause type, the action induced by the directive is typically temporally adjacent to the speech event. 


\section{GÓRALCZYK AND ŁOZIŃSKA}

Finally, let us note that, while we included a few recordings of actual yoga classes with students, the database for the corpus are mostly online tutorials, in which the yoga teacher faces the camera and is not interacting with any copresent practitioners, while still performing the postures as she or he speaks. We assume that this type of communicative situation is basically meant to reflect the interactive circumstances of in-person classes with students, which we have described above, only without reciprocal audibility and visibility. Thus, we shall assume that, insofar as the variety and force impact of the directives are concerned, any differences between their use in tutorials and face-to-face communication are negligible.

The corpus for the present study has been created by a random sampling of fully clausal instructions given by yoga instructors to their students, selected from yoga classes available on YouTube (as mentioned above, mostly yoga tutorials and a few recordings of actual classes with practitioners). ${ }^{4}$ The sample has been randomised in two ways. First, for each language thirty recordings have been chosen to ensure the balance in sample size. Each recording features a different yoga teacher in order to control idiolectal construction selection bias. Otherwise, the procedure followed a simple randomisation schedule, without controlling such covariates as age or sex of the yoga teacher. In practice, as it turned out, around $80 \%$ of the sampled tutorials were run by female teachers.

Second, taking into account the varying dynamicity of the respective phases of a yoga class, each recording was watched from three randomly chosen starting points, targeting the first half, the middle phase and the second half of the class each time. Ten clausal instructions were selected from each recording (three consecutive instances of fully clausal instructions from the first half, four from the middle, and three from the second half of the class). The randomisation schedule determined that the starting points on the consecutive recordings within each language were set well apart to avoid a repetition of the same phase of the training, yet we meant each such starting point to be treated as an approximation only, as sometimes fully clausal instructions occurred and were obtained later than at the starting point.

In this way, the randomised data include the instructions produced by different instructors used at different stages of yoga classes. To sum up, for each language thirty recordings were scrutinised, and from each of those ten sentences were selected, providing a 600-token corpus in total. Next, the data were coded for the language, person/number markings on the verb, and for the type of grammatical structure (including the mood-tense-aspect specifications). ${ }^{5}$

[4] Links to selected websites providing YouTube tutorials in Polish and Russian are listed in the Appendix.

[5] The database with tagging is available online $<$ https://osf.io/f2ykw/ $>$. 


\section{Results}

In confirmation of Hypothesis 1 and 2, the randomised sample of fully clausal structures employed to convey yoga instructions evidences some variation within each language and also between the languages. As it turns out, the corpus for Polish is almost exhaustively divided between two types of directives, i.e., imperatives (50\%) and imperfective non-past indicatives (45\%). The marginal $5 \%$ are the instructions employing perfective non-past indicatives with future time meaning. The range of clausal directives attested in our corpus for Russian includes three major constructions with the following distribution: imperatives - $21 \%$ instances; declaratives with imperfective non-past indicative verbs $-58 \%$; and, additionally, the declarative clause type in the indicative with the verb marked for the past tense $-19 \%$. The speakers of Russian only marginally selected the construction with the perfective non-past indicative verb form $(1 \%)$, the infinitive $(0.7 \%)$, and the structure with pust' $(0.3 \%)$. As the focal interest of the present analysis is in the three major constructions, we have decided to exclude the morphosyntactic patterns with a negligible share in the respective data from further quantitative and qualitative analysis.

Thus, the quantitative part of the analysis for the relevant data - with the shares of the two constructions in Polish and the three constructions in Russian re-calculated to sum up to $100 \%$ - reveals the distribution patterns within each language and between the languages shown in Figure 1.

As illustrated in Figure 1, in the Polish data, the imperfective non-past indicative construction is nearly as frequently selected as the imperative (47\% compared to $53 \%$, respectively). The re-modelled distribution of the three constructions in Russian proves the preference for imperfective non-past indicatives over imperatives and indicatives with the past tense inflection on the verb $(60 \%, 21 \%, 19 \%$, respectively).

As the analysis reveals, the differences in the frequency of use both within each language and between the languages are dramatic and statistically significant $\left(\mathrm{chi}^{2}\right.$ test of independence with Yates' correction for small values $=93.33$, $\mathrm{df}=2, \mathrm{P}<0.001)$. Furthermore, we wanted to find out if the quantitative difference between the use of exactly the same patterns, i.e., the imperative and the imperfective indicative non-past constructions, in Polish and Russian can plausibly be attributed to the distribution of the third construction conventionally selected by the speakers of Russian to convey a yoga instruction. Yet, when the data for Polish and Russian were analysed without the indicative past (the two remaining values for Russian were further recalculated so that they summed up to $100 \%$; see Figure 2), the difference was still statistically significant $\left(\chi^{2}=37.594, \mathrm{df}=1, \mathrm{P}<0.001\right)$.

Seeking to confirm Hypothesis 3 , in the discussion section of the analysis below we investigate how the examined constructions differ relative to each 


\section{GÓRALCZYK AND ŁOZIŃSKA}

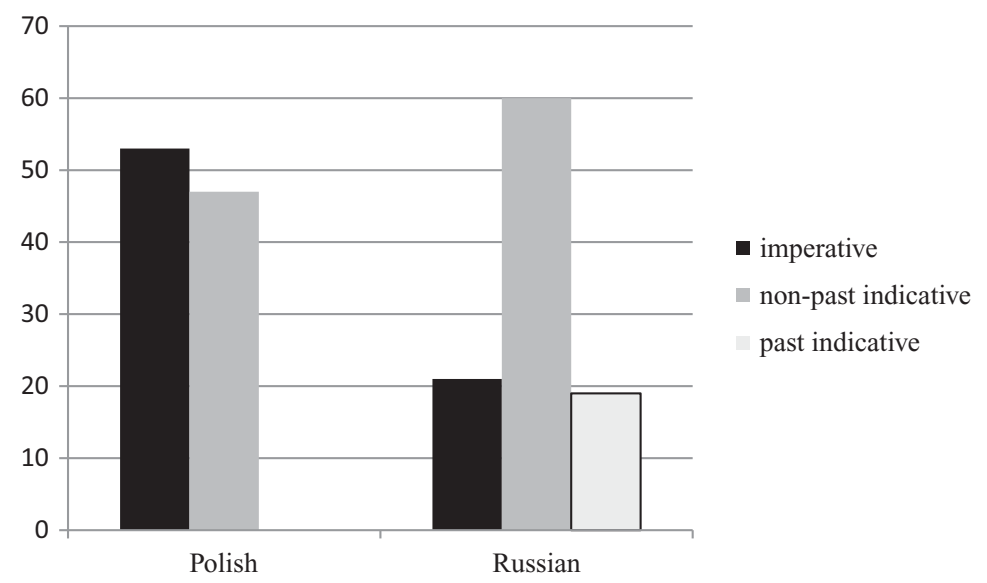

Fig. 1. Frequency of use of the imperative, the non-past indicative constructions in Polish and Russian, and the past indicative construction in Russian.

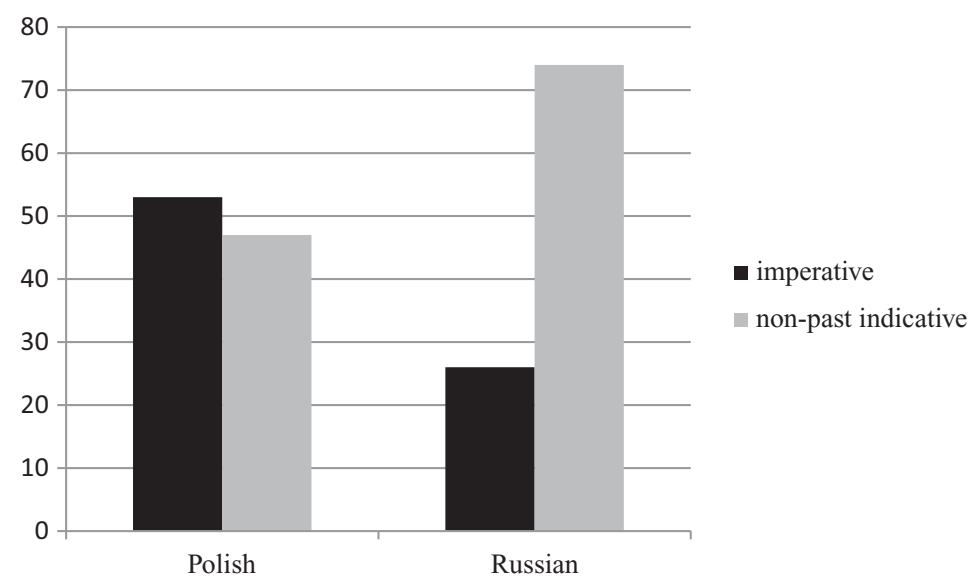

Fig. 2. Re-modelled frequency of use of the imperative and the non-past indicative constructions in Polish and Russian.

other / one another within each language, showing that the selection of one over another is far from random. We shall seek the locus of contrast in the respective conceptual make-ups of the constructions under consideration.

\section{Discussion}

Intuitively, when compared to directive force impact in a variety of other contexts of use, such as medical, educational, or military contexts, for example, 
yoga instructions are weak directives. In order to support such an assessment, let us briefly consider a few socio-cultural factors mentioned in Section 2, which contribute to a better understanding of the speaker-hearer interpersonal circumstances in which yoga instructions are employed to achieve the required interpersonal and interactional effects (e.g., Takahashi, 2012).

First, the yoga practitioner is perfectly willing to carry out the action expressed in the instruction as it is performed mainly for her or his benefit the teacher's wilfulness is based on altruistic support and encouragement for their students and, perhaps, their professional satisfaction. Further, even if performing the required asana is definitely far from optional and the instructions are imbued with some degree of obligation, there is no great pressure imposed on the yoga practitioner, and besides, as mentioned before, compliance is beneficial for the addressee. As for the power gap between the communicators, let us note that the relation between a yoga teacher and a yoga practitioner during a yoga class is obviously an asymmetrical relation of the teacher-student type. Hence, a yoga teacher stands in a relation of authority relative to a yoga practitioner. However, it appears that the authority status does not need to be invoked as the socio-psychological force pushing the hearer towards compliance cannot be rated as high. Finally, the cost of performing the intended action is typically relatively low as asanas are supposed to be pleasant and relaxing. The hearer is typically fully capable of doing them and the actions themselves are fully controllable.

To conclude, in light of the above characteristics, yoga instructions involve (relatively) low force exertion. That does not mean that they are equally weak throughout the class and that they cannot occasionally be more forceful, preparing the practitioner for more energy expenditure - and greater cost in some class phases. With these descriptions in mind, let us focus on each of the respective constructions individually.

\subsection{YOGA INSTRUCTIONS IN THE IMPERATIVE}

As the research has revealed, a vast part of the yoga instructions in Polish and a much smaller part of the data in Russian employ the imperative clause type, as in (6-7), respectively.

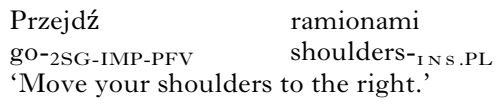

\begin{tabular}{|c|c|c|c|}
\hline Smotrite & glazami & sebe & za spinu. \\
\hline $\begin{array}{l}\text { look-2P L-IMP-I P F v } \\
\text { 'Look with your ey }\end{array}$ & $\begin{array}{l}\text { eyes-INs PL } \\
\text { ind your bacl }\end{array}$ & yourselves & behind back- ${ }_{\mathrm{Acc}} \mathrm{s} \mathrm{G}$ \\
\hline
\end{tabular}




\section{GÓRALCZYK AND ŁOZIŃSKA}

Schematically, the conceived scene evoked by a yoga instruction employing the imperative pattern includes as its salient elements the yoga instructor-Speaker $(\mathrm{S})$ - and the yoga practitioner - Hearer $(\mathrm{H})$ - who are engaged in a relation such that $\mathrm{S}$ exerts a (relatively low) degree of mental (interpersonal, sociopsychological) force directed at $\mathrm{H}$. The Speaker is thus the Force Agent (FA) and the Hearer is the Force Target (FT). Following Takahashi (2012, p. 13), we shall assume that inherent in this configuration are the force exertion component and hearer-directedness. In the expressed event, the Hearer is presented as the Agent (Ag) of the relevant future activity (A).

It is important to note that, while in the conceived scene the Speaker exerts a socio-psychological force on the Hearer with the aim of 'pushing' the Hearer towards the performance of the activity A, the mere idea of 'pushing' the Hearer does not presuppose that it will be successful. Nevertheless, part of the idealised cognitive model of a speech act such as an order is accepting the scenario and complying, while a decision not to comply is a departure from the model (Kochańska, 2011, p. 184). Given the characterisations of yoga instructions overviewed in the introductory part of this section, and especially the fact that compliance is beneficial for the practitioner, we shall assume that the above condition holds also for directives in the examined discourse genre.

On a final note at this juncture, it will be observed that the illocutionary force of an instruction in the imperative is not derived through the use of figurative language, nor does it rely on the hearer's inferential activity, as the future event profiled by the imperative represents the CORE component of the scenario. ${ }^{6}$

Focusing now on the meaning of the construction, it will be stated that, in light of Langacker's analysis, the semantic characterisation of the imperative follows from its function: the imperative is employed by the speaker to elicit an effective response from the hearer (2009, p. 156). According to Takahashi (2012, pp. 57, 71), the semantic components which appear to be essential for the schematic description of the category of the imperative are as follows: (a varying degree of) force exertion, the second person subject (prototypically, individuated, playing the semantic role of Causee/Agent), hypotheticality, and future orientation. The category of an illocutionary act conveyed by the construction in such a semantic description is left indeterminate. Put differently, the imperative does not always convey a directive speech act.

In Cognitive Grammar, the semantic import of any construction resides in the construal it imposes upon the scene of the conceptualised event. The conceptual configuration within the conceived scene evoked by the imperative,

[6] However, even if the interpretation of the utterance as an act of putting $\mathrm{H}$ under an obligation to do A does not rely on the hearer's inferential activity, the utterance needs to be viewed through the prism of the entirety of the scenario. 


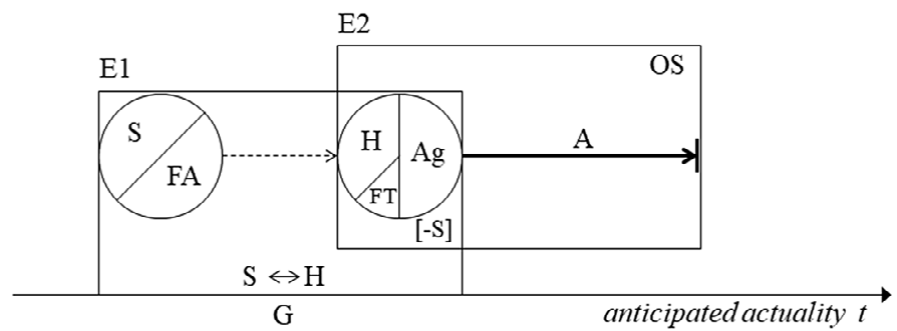

Fig. 3. The conceptual organisation of the scene in the imperative construction (adapted from Takahashi, 2012, p. 12).

also encompassing the pragmatic properties of a direct directive in yoga overviewed in Section 5 , is specified in Figure 3.

Following Langacker's (2008, p. 474) and Takahashi’s (2012, p. 13) analyses of the English imperative, we shall assume that the imperative construction in Polish and Russian expresses a complex event, or an action chain of two (sub) events E1 and E2 (in the sense of Langacker, 1991, pp. 283, 293, whereby temporally or causally sequenced event subcomponents can be treated as forming a natural path).

As illustrated in Figure 3, Event 1, which encompasses a relevant portion of the ground $\mathrm{G}$, occurs prior to, and causes, Event 2, which is the utterance event. In the causing event, the yoga instructor (the Speaker / Force Agent) exerts interpersonal (social and psychological) force directed at the individuated yoga practitioner (the Hearer / Force Target), putting them under some degree of obligation to perform the required asana as Agent (Ag). In other words, E1 conveys the Speaker's effective stance in regard to the process expressed in E2, i.e., her or his intention to bring about the occurrence of this process (Langacker, 2008, p. 474). (Relatively low) force impact carried by the imperative clause in the discourse genre under investigation is represented by a rightwards dashed arrow between $\mathrm{S} / \mathrm{FA}$ and $\mathrm{H} / \mathrm{FT} / \mathrm{Ag}$.

In $\mathrm{E} 2$, the primary figure within the scene is the yoga practitioner $(\mathrm{H} / \mathrm{FT})$ in the semantic role of an Agent $(\mathrm{Ag})$, who is conceptualised as engaged in performing the activity A. As a formal (structural) exponent of an imperative clause, the subject is by default left unexpressed, which is represented by an off-black circle marking the action chain head in E2. Put in conceptual terms, the trajector of the profiled process is conventionally not explicitly coded by any subject NP.

As the direction of the timeline $t$ indicates, E2 is a future-oriented event. Specifically, as anticipated by the Speaker, it is an event located in the projected future in reality (as an actual event, see further Section 5.2.). Let us note that it is not anchored to the ground $\mathrm{G}$ independently of E1. As argued by Langacker, imperatives "conflate the functions of clausal grounding and illocutionary 


\section{GÓRALCZYK AND ŁOZIŃSKA}

force” (2009, p. 158). Parallel claims have been made for Polish, whereby the inflection which is specialised for the imperative mood is treated as a grounding predication that profiles a process anchored in the speaker's intent (the effective grounding) (Kochańska, 2011, p. 187, 2015, p. 70). Premised upon the typological similarity of Polish and Russian, we make the same assumption about the status of the imperative inflection (the person-number markings specialised for the imperative) as a grounding predication for Russian as well. As observed by Langacker, the effective grounding shapes the epistemic grounding, as "something not yet affected is not yet real" (Langacker, 2008, p. 474; Kochańska, 2015, p. 70).

As shown in our data, the process profiled in $\mathrm{E} 2$ is conventionally encoded by a verb in the perfective aspect $(90 \%[\mathrm{Pl}], 78 \%[\mathrm{Ru}])$. As convincingly argued by Kochańska (2002, pp. 351-352), in Polish and some other Slavic languages a perfective verb is prototypically selected when the process it expresses is conceived of as completed. In contrast, an imperfective verb prototypically encodes an ongoing process. As further observed by Kochańska, the imperfective may also designate a process which is conceptualised as completed, yet its final state is then viewed as not obtaining at the time of speaking (2002, pp. 351-352).

The aspectual opposition between the perfective and the imperfective in Russian, and more generally in East Slavic languages, differs considerably from the contrast discussed above in Polish and is apparently "typologically very unusual” (Dickey, 2020, pp. 544, 574). According to Dickey, the prototypical meaning of the perfective aspect in Russian is an instantiation of the schema of temporal definiteness, whereby an event coded by means of a perfective verb is "some kind of whole" that is unique, or "qualitatively different from the preceding and subsequent state-of-affairs" in a temporal and causal sequence of events (2020, p. 544). It will be noted that Dickey's account challenges traditional analyses, whereby the perfective aspect is taken to express the totality of the event involving a change of situation when viewed from the observer's deictic viewpoint (2020, p. 546).

As has been further argued by Dickey, the imperative construction 'adds' a distinct component to the temporal sequencing of events contributed by the perfective construction, which is a moment given to the hearer so that she or he can decide whether to perform the requested action (2020, p. 555). Put differently, it is part of the schematic meaning of the construction that, by selecting the perfective imperative, the speaker intends to give the hearer an opportunity to consider the request, choose to comply, and then carry out a complete single action with a desired outcome. ${ }^{7}$

[7] This brief overview cannot do any justice to extensive research on the Russian imperative (e.g., Gusev, 2013; Xrakovskij \& Volodin, 1986/2001; for a discussion of a number of works, see Dickey, 2020). 
The core property common to the perfective imperative in both Polish and Russian, whereby the event that the construction expresses is construed as a completed whole, is marked in Figure 3 as A including a blocking black bar.

The preference for perfective verbs in both languages apparently contributes to the force impact of the imperative construction - the Speaker 'pushes' the Hearer to (make a choice to comply and) complete the required activity, while the final phase is typically invoked.

Let us further observe that in the imperative construction the speaker herself or himself is not conventionally construed as part of the onstage region - one instance of $1 \mathrm{PL}$ is attested in the corpus for Polish and none for Russian. Thus, as part of the schematic characterisation of the Agent in E2 we have added the specification of $\mathrm{Ag}$ as speaker-exclusive [-S].

As follows from the descriptions offered above, certain aspects of the ground $\mathrm{G}$ (the Speaker's intent or valuative attitude, and the Hearer) receive a partially objective construal in E1. By the same token, certain aspects of the onstage region (OS) encompassing $\mathrm{E} 2$ receive a partially subjective construal (the Agent of the relevant activity A).

On a final note, while the construction necessarily encodes the Speaker's perspective, the relation between the communicators should more precisely be viewed as expressing a cognitively and socially negotiated Speaker-Hearer (intersubjective) perspective, which is represented by a left-right arrow between $\mathrm{S}$ and $\mathrm{H}$ within the ground $\mathrm{G}$.

\subsection{YOGA INSTRUCTIONS IN THE IMPERFECTIVE NON-PAST I N D I C A T I V E}

As the quantitative part of this research has shown, yoga teachers, both Polish and Russian, rely heavily on the use of the imperfective non-past indicative pattern. For illustration, consider the examples in (8-9):

I robimy pompki.

and do-1PL-IND (N ON-PAST)-I P F V

'And we do push-ups.'

\footnotetext{
Opuskaem

lower-1PL-IND (NON-PAS T)-I M P F

'We lower the chin onto the chest.'
}

[Pl]

push-up- A C C P L $_{\text {C }}$

podborodok na grud'. [Ru] chin- ${ }_{\text {Acc.SG }}$ onto chest-Acc.sG

At its core, the pragmatic characterisation of the examined construction is comparable to that of the imperative insofar as it pertains to the causal relation between E1 and E2; the configuration within the ground G, whereby the Speaker / Force Agent exerts (relatively weak) mental force upon the Hearer / Force Target, putting them under some degree of obligation to perform the 


\section{GÓRALCZYK AND ŁOZIŃSKA}

required activity as Agent; and, finally, the conceived future-time event of the Hearer performing the relevant activity (E2).

However, in contrast to the imperative, the illocutionary force of a yoga instruction in the imperfective non-past indicative is clearly derived via figurative use of language. We shall argue that any such instruction expresses a perlocutionary effect, and consequently the AFTER component of the scenario, in a special viewing arrangement described below. The inferential activity in meaning construction leads to the interpretation that the description of the perlocutionary effect is in actual fact a persuasive act of force exertion by the Speaker / Force Agent upon the Hearer / Force Target. The inferential path is facilitated by the underlying metonymic mapping from the trigger, i.e., the A F T E R component of the scenario, to the target, i.e., the scenario as a whole, compelling the Hearer to perform the activity A, in the PART FOR W HOLE metonymy.

On a final note at this juncture, let us observe that, as directive uses of the imperfective non-past indicative in Polish and Russian are apparently conventionalised in the two languages, the mechanism of metonymic inferencing should no longer be viewed as the mechanism of interpreting the relevant utterances by the hearer locally, in the here and now of the speech situation, but rather as the mechanism motivating, or facilitating, the emergence of the relevant conventionalised meanings.

In proceeding further, let us note that the semantic import of the imperfective non-past indicative construction derives from the semantics of the declarative clause type, the indicative mood, the non-past tense, in an interaction with the imperfective aspect. We shall briefly overview the meanings that these grammatical patterns evoke.

In contrast to other sentence types, a declarative clause delivers a representation of the world's facts. It is then conventionally associated with assertion and the word-to-world direction of fit. Yet, as argued by Siemund, the pattern can be used with "practically all imaginable illocutionary forces" (2018, p. 127). Therefore, assertive force is not part of the semantic import of the construction, which is instead described as force-neutral (Recanati, 1987, pp. 163-169; Siemund, 2018, pp. 135-136).

In a cross-linguistic perspective, the mood markings on the verb in the declarative clause indicate the speaker's epistemic attitude with respect to the mood - realis or irrealis - of the proposition expressed by the declarative clause. In other words, by selecting the indicative mood in the construction at hand, the speaker signals their perspective that they can present the content of the proposition as a possible element of reality (Achard, 1998, p. 225). It has to be added that in the systems of both Polish and Russian the indicative is the unmarked mood. 
Further, while the mood locates a given event vis-à-vis reality, the tense system of a language locates the event in time in relation to the moment of speech or in relation to an established temporal reference point. In both Polish and Russian, a distinction is made between past and non-past, marked with person-number inflection. Finally, part of the meaning of the construction at hand is contributed by the (lexically marked) imperfective aspect (see also footnote 2).

To recall from the previous discussion in Section 5.1., in Polish and some other Slavic languages the imperfective aspect is prototypically selected to encode a process which is conceived of as ongoing (not completed), or when its final state is not obtained at the time of speaking (Kochańska, 2002, pp. 351352).

According to Dickey's model of the aspectual opposition between the perfective and the imperfective in Russian, when the imperfective verb form is employed, the sequential and causal structuring of qualitatively different events, i.e., the temporal definiteness of the expressed event, is cancelled (see Section 5.1). The imperfective is thus used in three prototypical situations: (i) when it encodes an ongoing process; (ii) when the situation is construed as a habitual repetition; and finally, (iii) when the expressed event, completed or not, is isolated from its temporal context, or the temporal context is defocused (2020, pp. 544-545).

As argued by Kochańska in her analysis of the construction in Polish, uses of the imperfective non-past for future-time occurrences involve a special viewing arrangement, to be explained below (2002, pp. 360-369). We shall claim that the construction in Russian evokes a comparable configuration on the scene of the conceptualised complex event.

The conceptualisation evoked by a yoga instruction employing the imperfective non-past indicative construction, in Polish and Russian alike, is specified in Figure 4 (adapted from Kochańska, 2002, p. 367). As illustrated in Figure 4, the construed temporal sequencing of E1 and E2 radically departs from their arrangement in Figure 3. E2 is construed and represented in the figure as coincident with the configuration within the ground $\mathrm{G}$ encompassed by E1. Following Kochańska (2002, pp. 360-369), we shall elucidate the conceived scene evoked when the imperfective non-past indicative is used in terms of the contrast between virtual and actual events (in the sense of Langacker, 1999, pp. 97, 99).

In coding E2, the imperfective non-past construction is clearly used with immediate future-time reference. As argued by Kochańska, the selection of the construction means that the speaker is only indirectly concerned with the occurrence of the profiled event in the future in reality (as an actual event). Instead, the profile is shifted from the actuality plane (in the future) to the virtuality plane, whereby the virtual counterpart of the actual event is 


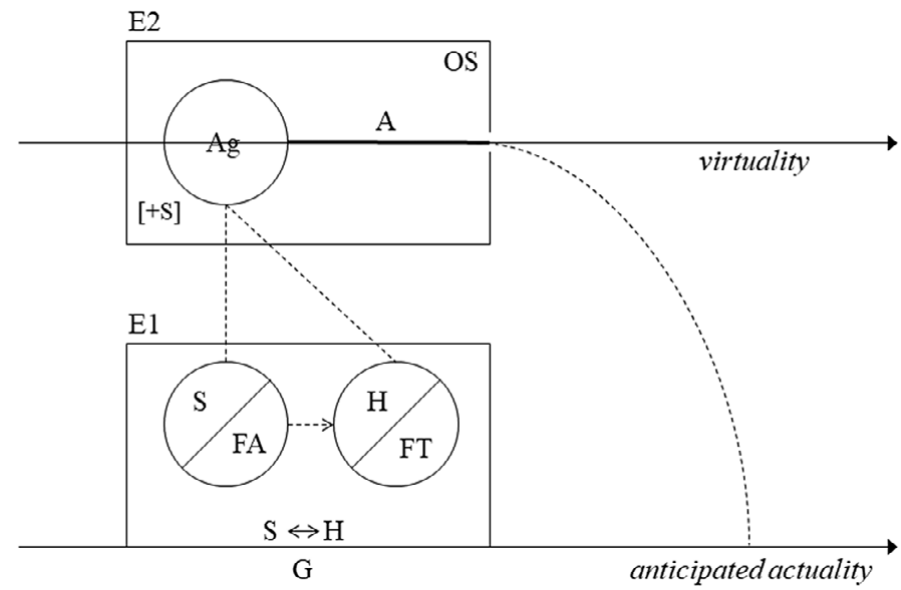

Fig. 4. The conceptual organisation of the scene in the imperfective non-past indicative construction.

presented as initiated at the time of speaking (2002, pp. 360-369). In Langacker's own terms, a virtual counterpart of an actual event should metaphorically be thought of as a record in a mental representation of scheduled events, or a virtual document with entries that represent processes in events which are planned to occur in the future (Langacker, 1999, p. 94, Kochańska, 2002, p. 362). Typically, this kind of viewing arrangement pertains to habitual, planned, or scheduled events, and such events that occur as a normal course of events, in both Polish and Russian (Grenoble, 1989, p. 99; Kochańska, 2002, p. 363). When the construction is used in the situational context of yoga, the profile is shifted from an actual event in the immediate future (the conceived A F T E R component of the illocutionary scenario) to its virtual record which is 'read off' at the speech time. To be more specific, the profiled virtual event is activated at the time of speaking and is conceived of as ongoing, or - when the conceptualised event is completed - its final phase is not invoked (the meaning 'added' by the imperfective aspect). Under such an arrangement, the speaker assumes immediate and automatic acceptance of the record of the event in the virtual document at the moment of its presentation to the hearer so that the record can be activated at the time of speaking (Kochańska, 2002, pp. 363364). As further explained by Kochańska: "Activating a record at the time of speaking results in the virtual occurrence of a process that is co-extensive with the speech event" (2002, p. 364).

The force impact of a yoga instruction employing the imperfective non-past indicative construction, whereby the automatic and immediate acceptance by the Hearer of the relevant E2 is taken for granted, is weakened by the Speaker 
putting herself or himself on stage as the co-addressee of the directive. Thus, any power imbalance that might be invoked is reduced as the Speaker is put under the same strain of (relatively weak) pressure as the Hearer. In the examined construction, in the conceived scene, the Speaker chooses to put herself or himself on stage dramatically more often than in the conceptualisation evoked by the imperative construction. Specifically, as our data reveal, in Polish the speaker-inclusive construal of the Agent is attested in $80 \%$ of cases, while in Russian it is attested in $90 \%$ of cases. The selection of the speakerinclusive construal of the Agent of the activity A apparently contributes to the construction's force impact. Thus, as part of the schematic characterisation of the Agent in E2 we have added the specification of $\mathrm{Ag}$ as speaker-inclusive $[+\mathrm{S}]$.

\subsection{YOGA INSTRUCTIONS IN THE PAST INDICATIVE IN RUSSIAN}

In their typological research on the declarative clause, König and Siemund (2007, p. 281) state that in its primary function it conveys "the belief of the speaker that the proposition is true or will turn out to be true". They add that a number of extra conditions have to be met for a declarative clause to carry directive meaning, and they list, among other factors, a non-past tense. In light of our findings, König and Siemund's observation about the distribution in directive declaratives of non-past tenses solely appears to be challenged by the data from Russian. ${ }^{8}$ Nearly one-fifth of yoga instructions in our corpus of Russian are expressed as a declarative clause in the indicative mood with the perfective verb inflected for the past tense, as in (10):

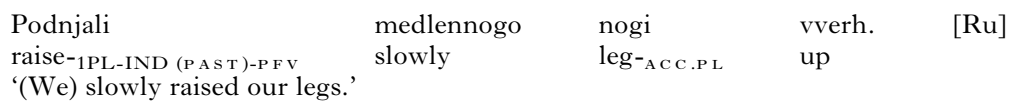

Research on the use of the perfective past with future reference in Russian is scarce. Most mentions focus on the colloquial style of such a grammatical form or the construction's use under special politeness conditions, whereby it is selected to convey a very authoritative and, most often, purposively rude command, as pošel past-pFv von 'get out of here', for example (Belikov, 2001; Belošapkova, 1997, p. 560). This variant of the construction - with a

[8] Apparently, cognate past tense directive constructions are part of the grammatical systems of other Slavic languages as well, which fact passed unnoticed in the typological studies by König and Siemund (2007). Mel'ničuk lists also Czech and Ukrainian, for example (1966, p. 77). Just as in Czech and Ukrainian, in which the use of the construction appears to be oldfashioned, an in-depth analysis of the Polish cognate construction would need to include questions about its productivity, among others. 


\section{GÓRALCZYK AND ŁOZIŃSKA}

speaker-exclusive form of address - contrasts with instances of use in which the addressee is speaker-inclusive and when the profiled activity is of positive value. The utterance is then no longer perceived as abrupt and harsh. Belikov relates the difference in the pragmatic effects to power (im)balance among the communicators in the situational context of use (2001, p. 162).

One of the contexts in which the perfective past construction is widely used to convey imperative meaning is the teaching context; note such classroom

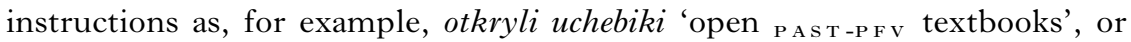

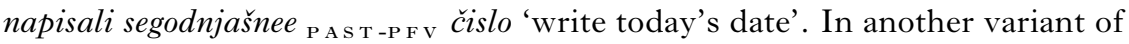
the construction, past tense perfective verbs of motion can be used to express an event about to occur in the imminent future with "rather hortative"

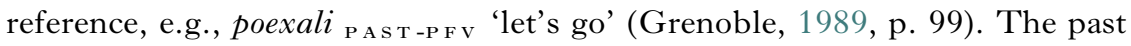
tense is in such use more colloquial than non-past. The directive use appears to be similar to that variant.

At its core, the pragmatic characterisation of the past indicative construction used for yoga instructions is comparable to the previously discussed patterns: $\mathrm{E} 1$ and $\mathrm{E} 2$ are locked in a causal nexus $\mathrm{E} 1 \rightarrow \mathrm{E} 2$; the configuration of the participant roles of Force Agent and Force Target remains the same - the Speaker exerts relatively weak pressure upon the Hearer, 'pushing' her or him to perform a relevant asana in the immediate future. In E2, similar to the imperfective non-past indicative construction, the illocutionary force of a directive is realised via figuration based on the illocutionary scenario. Specifically, the utterance event E2 expresses behavioural response (a perlocutionary effect), and consequently the AFTER component of the scenario. In the situational context of use, with all the clues available to the addressee of the directive, this part triggers mental access to the whole illocutionary scenario. In other words, inferential activity on the part of H/FT is here facilitated by the underlying PART FOR W HOLE metonymy. Finally, as has been observed in relation to the previously discussed construction, directive uses of the indicative past in Russian appear to be fully conventionalised in the discourse of yoga, in addition to other contexts of use that have been discussed above. Thus, in such contexts metonymic inferencing apparently facilitates the emergence of the relevant conventionalised meanings.

In proceeding further, let us note that Mel'ničuk seeks the historical origin of the patterns with imperative meanings such as Pošel von!, Vzjali!', Pošli s nami! in the construction with the particles $a$ and $b y$, as in Old Russian $A m y$ dokol xočem ruskuju zjemlju gubit'? A byxom sja uladili' (1966, p. 76). The particle $b y$ derives from $b i(m)$, which marked the optative in Proto-Slavic, and which was further fused with $b y(h)$, which marked the aorist (1966, p. 76). As argued by Mel'ničuk, the particle was then omitted to produce the imperative meanings conveyed by the remaining perfective verb forms (1966, p. 77). 


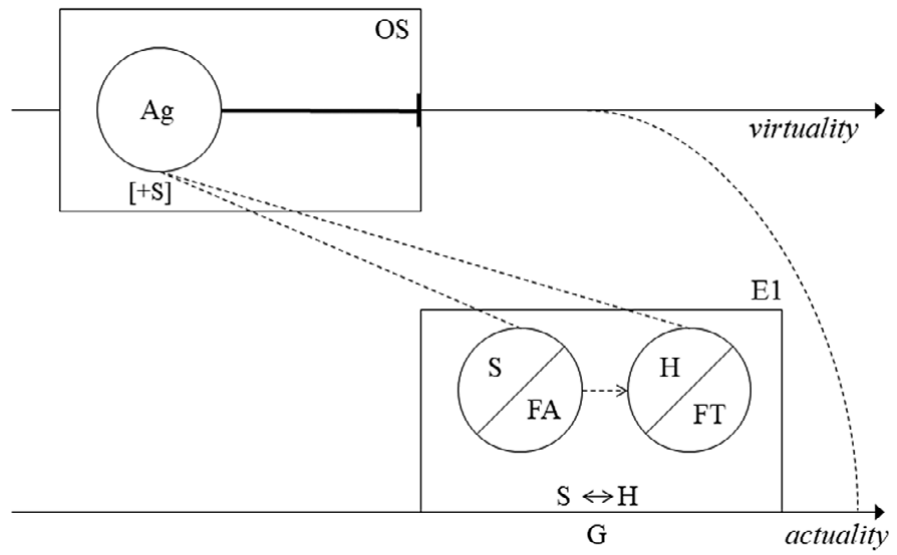

Fig. 5. The conceptual organisation of the scene evoked by the indicative past directive.

In light of the above, insofar as the analysis is extendable to the construction employed in yoga instructions, it is doubtful whether - despite its form in present-day Russian - the construction includes as its meaning component the prototypical meaning of the past tense in the indicative mood, which is an assertion of a past fact (in actuality). Instead, we shall suggest that the meaning contributed by the past tense form of a verb lexicalising the construction should be viewed through the prism of the temporal definiteness evoked by the perfective aspect (see Section 5.1) (Dickey, 2020, pp. 544-546). Specifically, given that the perfective signals a sequential conceptualisation of time, whereby events are arranged in a succession with respect to one another and irrespective of the observer's deictic viewpoint (2020, p. 546), it will be claimed that the past tense may be employed to denote precedence of an event in virtuality and not its pastness relative to a point of reference in actuality. Note also that the event expressed by the perfective is construed as a completed whole.

The conceptual architecture of the conceived scene evoked by the directive use of the indicative past construction in Russian, which is employed to refer to an immediate future-time occurrence, is specified in Figure 5. As illustrated in Figure 5, the profile of E2 is shifted from the future event in the actual plane to its virtual record in a virtual document. We shall very generally describe this virtual document as a simulation of the future event in the actuality plane. In the virtual record, the Hearer is construed as the Agent who completed the activity $\mathrm{A}$, while the utterance event $\mathrm{E} 2$ precedes the force exertion event $\mathrm{E} 1$. It will be observed that presenting an as yet unrealised event as a fully realised occurrence preceding the utterance event appears to be a case of the conceptualiser's effort to persuade H/FT to comply, rather more forceful than mere 


\section{GÓRALCZYK AND ŁOZIŃSKA}

'pushing' or taking for granted immediate compliance evoked by the previously discussed constructions.

Finally, given that Russian is a partially pro-drop language (Biberauer et al., 2010, p. 11), let us note that in our data the trajector of the process is invariably left unexpressed (represented in Figure 5 as an off-black circle). As the past tense inflection on the verb in Russian makes no formal distinction between $1 \mathrm{PL}$ and $2 \mathrm{PL}$, the meaning of the construction is potentially ambiguous with respect to the addressee of the instruction - between the speakerinclusive and speaker-exclusive readings (3P L is by default excluded in the situational context of use). In light of some claims which have been made in the research on the use of the perfective past for future-time occurrences in Russian that pertain to the semanto-pragmatic distinction between the speaker-inclusive and speaker-exclusive readings - as previously discussed in this section - under the conditions of use in the context of yoga, the agent in the profiled activity will necessarily be construed as speaker-inclusive. This aspect of construal apparently contributes to the construction's force impact. Putting the Speaker under the same strain of (relatively weak) pressure as the Hearer weakens slightly the force of the directives. Thus, the specification of $\mathrm{Ag}$ as speaker-inclusive has been included into the schematic characterisation in $\mathrm{E} 2$.

\subsection{WITHIN-AND BETWEEN-LANGUAGE DIFFERENCES IN DIRECTIVE FORCE I M PACT}

It becomes apparent in light of the analysis developed in the preceding sections that the examined constructions differ in the strength of the imposition when viewed through the prism of a few aspects of construal. These pertain to: (i) the actual/virtual status of the record of the event evoked when the respective construction is used; (ii) the Speaker's presence in the onstage region or the lack thereof; and also (iii) the aspectual specification of the process as ongoing (initiated) or completed (with the final phase invoked). Let us briefly summarise the fundamental details of the respective conceptual make-ups of the constructions under scrutiny.

In the imperative, the conceived scene involves the idea of the Speaker exerting force with the aim of 'pushing' the Hearer to perform the relevant activity. The utterance event presents an actual event in the immediate future as it is projected (or conceived of) by the Speaker. Crucially, the Hearer's complying with the instruction is not presupposed or automatically assumed. To recall, in the perfective imperative in Russian, the Hearer's decision to comply is allowed an additional time unit in the temporal sequence of events evoked schematically by the construction. Accepting the scenario and acting accordingly - especially that complying is beneficial for the addressee of the 
directive - is a default arrangement, but the conceptual content to this effect is supplied by a separate cognitive model. In this respect, the imperative encodes the weakest force impact. Furthermore, the profiled event is viewed as completed, yet without setting any temporal boundaries (apart from the general assumption of immediacy, which is easily available for the addressee of the directive in the situational context), it does not seem to affect the force impact of the construction to a high degree. Finally, the Agent is construed as speakerexclusive, which may be a factor contributing to a somewhat stronger force of the pattern (yet, as we shall see further in this section, it may also be attributable to contextual factors).

In the imperfective non-past indicative, the conceived scene involves the Speaker 'pushing' the Hearer to perform the activity A, in addition presenting to the Hearer a virtual record of the event, whereby the Hearer initiates the relevant activity $\mathrm{A}$ at the very moment of its presentation to her or him, ensuring that the record can be read off. Thus, the Hearer's immediate and automatic acceptance is taken for granted and the conceived degree of optionality left for the Hearer is much smaller. Hence, the force impact evoked by the construction appears to be stronger. Yet, putting the Speaker onstage in a speaker-inclusive construal of the Agent in the activity A, who thus shares the strain of the pressure, apparently weakens the force of the directive to a degree. Also, the fact that the event is construed as initiated at the moment of speaking and ongoing (not completed, or at least the final phase of it is not invoked) appears to contribute to the construction's force impact, by weakening it (in relative terms). All in all, the force impact of instructions evoked by the two constructions above appears to be comparable, and weaker than the force impact of the third construction, recapitulated below.

In the perfective past, the conceived scene involves the Speaker exerting force upon the Hearer with the aim of 'pushing' her or him to perform the relevant activity, in addition presenting to them a virtual record of the event whereby, preceding the presentation, the Hearer has already complied and acted accordingly. Thus, the record can be read off as a fully realised occurrence. Construing the virtual event in such a manner leaves the Hearer no optionality, and hence the force impact evoked by the construction is rather stronger than in the cases previously discussed. Let us note that the perfective aspect appears to further strengthen the impact. What apparently weakens it to a degree is the construal of the Agent of the activity A as speaker-inclusive, whereby the Speaker and the Hearer alike are put under pressure, with no optionality left to them. In Table 1 we summarise the key features of the examined constructions, with a view to illustrating more clearly how they divide between themselves the 'ecological niche' of weak directives in the studied discourse genre in Polish and Russian. 
T A B LE 1. Properties of directive constructions in yoga in Polish and Russian

\begin{tabular}{|c|c|c|c|c|}
\hline Construction & Reality & Agent & Aspect & $\begin{array}{l}\text { Hearer's } \\
\text { compliance }\end{array}$ \\
\hline Imperative & $\begin{array}{l}\text { Actuality (projected } \\
\text { future) }\end{array}$ & $\begin{array}{l}\text { Speaker- } \\
\text { exclusive }\end{array}$ & Perfective & $\begin{array}{l}\text { Not } \\
\text { presupposed }\end{array}$ \\
\hline $\begin{array}{l}\text { Non-past } \\
\text { indicative }\end{array}$ & Virtuality & $\begin{array}{l}\text { Speaker- } \\
\text { inclusive }\end{array}$ & Imperfective & Presupposed \\
\hline Past indicative & Virtuality & $\begin{array}{l}\text { Speaker- } \\
\text { inclusive }\end{array}$ & Perfective & Presupposed \\
\hline
\end{tabular}

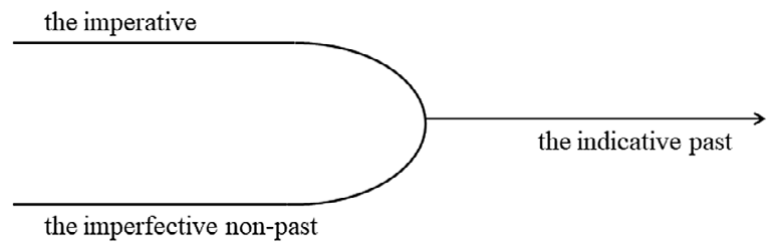

Fig. 6. The parameter of relative force impact oriented from weaker to stronger.

If the analysis offered above is on the right track, the parameter of relative force impact in the studied constructions can be described as the cline shown in Figure 6, oriented towards the impact growth. We will conclude that Polish has at its disposal the relatively 'weaker' instruction types, while in Russian there is additionally a choice of a relatively more forceful construction.

Furthermore, we were curious to compare the grammatical patterns of instructions issued in two standard phases of a yoga class: a dynamic warmup sequence and a relaxation sequence of instructions. Let us first explain the situational context of use of the instructions in both phases.

A yoga class starts with a warm-up routine, which consists in performing a series of asanas. The warm-up, which is called Surya Namaskar, is typically performed dynamically and the required postures come in quick succession. Let us note, however, that, Surya Namaskar may occasionally be performed at a slower pace. ${ }^{9}$ Each class finishes with a relaxation stage, when the practitioners lie flat on their backs, with their eyes closed. When the practitioners remain in this position, which is called Savasana, the instructor typically directs their attention to body parts, one by one, with the intention of

[9] The yoga terms which have been used in the analysis are as follows (after yogapedia $<$ https:// www.yogapedia.com>): asana - any physical yoga posture, found in all styles of yoga practice; Savasana - a key component of asana practice which is most commonly used at the end of a sequence as a means of relaxation and integration; Surya Namaskar - a specific sequence of yoga asanas, known as a Sun Salutation; namaste - a salutation. 
T A B LE 2. Distribution of the constructions in Surya Namaskar and Savasana in Polish and Russian

\begin{tabular}{lllll}
\hline Class phase & \multicolumn{2}{c}{ Suria Namascar } & \multicolumn{2}{c}{ Savasana } \\
\hline The imperative & $3[\mathrm{Pl}]$ & $1[\mathrm{Ru}]$ & $17[\mathrm{Pl}]$ & $16[\mathrm{Ru}]$ \\
The imperfective non-past indicative & $17[\mathrm{Pl}]$ & $19[\mathrm{Ru}]$ & $2[\mathrm{Pl}]$ & $4[\mathrm{Ru}]$ \\
The past indicative & $\mathrm{n} / \mathrm{a}$ & $0[\mathrm{Ru}]$ & $\mathrm{n} / \mathrm{a}$ & $0[\mathrm{Ru}]$ \\
Other & 0 & 0 & 1 & 0 \\
\hline
\end{tabular}

encouraging the practitioners to consciously relax them. Asanas are performed at a slower pace, which we assume goes with less forceful instructions.

Unfortunately, as the tutorial class naturally unfolds the (sequences of) asanas are very often not named and not individuated. We were thus unable to convincingly select the relevant material from our corpus. Instead, we randomly sampled four additional YouTube tutorials in each language which are devoted particularly to Surya Namaskar and Savasana. The sample is very small (20 clausal instructions in each language) and the study is not meant to support any far-reaching conclusions. Yet a very clear distribution pattern emerges, as seen in Table 2. As the data in Table 2 reveal, dynamic and energising yoga poses in Surya Namaskar are encouraged by the teacher by means of instructions which are only rarely in the imperative, in Polish and Russian alike. For illustration, see the samples below.

Stajemy na początku maty, robimy wdech i unosimy ręce. Na wdechu skłon, dotykamy rękami maty, patrzymy przed siebie, jeszcze głębszy skłon. [Pl]

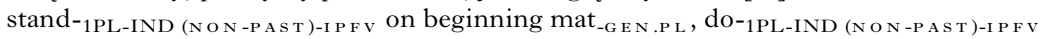
breath $_{-A C C . S G}$ and raise-1PL-IND (NON-PAST)-IPFV hand ${ }_{-A C C . P L}$. On inhale bend ACC. $_{-A}$. SG, touch-1PL-IND (NON-PAST)-IPFV hand INS.PL mat $_{-G E N . S G}$, look-1PL-IND (NON PAST)-IPFv front yourself, and even deeper bend ${ }_{-A_{C C . S G}}$

'We stand at the beginning of the mat, we breathe in and raise hands. On the inhale (we make) a bend, we touch the mat with our hands, we look ahead, and (make) an even deeper bend'

\footnotetext{
Vstaem na noski, dyšim, progibaemsja, smotrim vverh ...

stand-1PL-IND (NON-PAST)-IPFV on toe-ACC.PL, breathe-1PL-IND (NON-PAST)-IPFV, bend-1PL-IND (NON-PAST)-IPFV, self, look-1PL-IND (NON-PAST)-IPFV Up

'We stand on the toes, breathe, bend, look up ..."
}

When the yoga teacher requires the practitioner to respond in a more dynamic way, more energy needs to be summoned to follow, and consequently more forceful instructions need to be issued. We shall seek the motivation for the use of the imperfective non-past indicative construction in Suria Namaskar in the following aspects of the construction's characterisation: (i) a relatively 


\section{GÓRALCZYK AND ŁOZIŃSKA}

stronger force impact evoked as the Speaker assumes the Hearer's compliance and taking immediate action; and (ii) the speaker-inclusive construal of the Agent performing the relevant activity A. Such a construal is in harmony with the situational context, whereby the teacher demonstrates the pose and is typically actively involved in performing the relevant activity herself or himself.

It appears that another property of the construction, i.e., the construal of the relevant activity $\mathrm{A}$ as ongoing, does not really seem essential in this context of use. Let us also note that, when the construction is employed in instructions to perform a quick succession of actions, the relevant actions can only be understood to occur in succession if each is at least terminated, if not completed, when the next follows, but not that it is ongoing. In contrast, the preferred pattern of instruction for relaxing yoga asanas in Savasana is the imperative, irrespective of the language, as in the sequences below:

Zamknijcie oczy i przejdźcie uwagą do prawej stopy. Rozluźnij prawą stopę, łydkę kolano. Rozluźnij lewą stopę, łydkę, kolano ...

close-2P L-IMP eye-Ac c.PL-PFV and through-go-2P L-IMP-P FV attention-IN ${ }_{\text {IN T.SG }}$ to

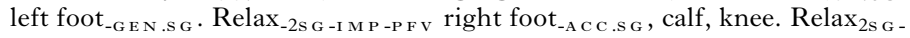
imp-PFv left foot ${ }_{-A C C . S G}$, calf $_{-A C c . s G}$, knee ${ }_{-A C C . S G}$

'Close your eyes, and direct your attention to your right foot. Relax your right foot, calf, knee. Relax your left foot, knee, calf ...'

(14) Ložites' na kover, ljagte udobno i komfortno, položite nogi na širinu pleč, a ruki na širinu kovra. Myslenno vnimaniem projdite po telu, s verhu vniz i s nizu vverh. Pust' telo stanet odnorodnym i celostnym. Soberite vnimanie i naprav'te v centr stop, rasslab'te centr stop.

lie-2PL-IмP-IPF on mat-Acc.sG, lie-2PL-IMP-PFv nicely and comfortably, put-2PL-IMP-PFV leg-ACC.PL on width back- ${ }_{\text {GEN.SG }}$, and hand- ${ }_{\text {ACC.PL }}$ on middle- $_{\text {ACC.SG }}$ mat $_{\text {GEN.SG }}$. Thinking attention-INS.SG go-2PL-IMP-PFV along body-DAт.s G from top down and from bottom up. Let body-Nom.s become-3SG-IND (NON-PAST)-P F homogenous and integral. Gather-2PL-IMP -

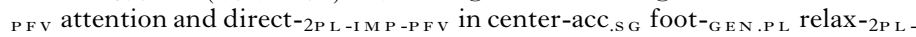
IMP-PFV centre-ACC.SG foot GEN.PL. $_{\text {I }}$.

'Lie on the mat, lie nicely and comfortably, put your legs on the width of your back, and your hands in the middle of the mat. In thoughts move your attention along the body from up to down and from down to up. Let the body become homogenous and integral. Gather the attention and direct it to the center of your feet, relax the center of your feet.'

We shall seek the motivation for the attested distribution of the imperative in Savasana in the following aspects of construal evoked by the construction: (i) a relatively weak impact, leaving the Hearer a conceived degree of optionality needed for performing the activity; (ii) the type of activity, whereby some mental effort is required to complete the activity $\mathrm{A}$ that cannot be done instantly and automatically; and (iii) the speaker-exclusive construal of the 
addressees of the directive, who are left lying on their backs with their eyes closed, remaining the sole agents performing the activity A.

It may come as a surprise that in Russian no uses of the past indicative were attested in the examined suryas. In the main corpus of the data, the increased use of the indicative past construction was noted in contexts in which the instructions apparently signal some changes in the dynamicity of the exercise. For illustration, in (15) below, in the initial posture, following the directive in the imperfective non-past indicative, the practitioner remains stationary. The series of postures that follow require relatively more energy and the yoga teacher selects the perfective past construction in order to issue a more forceful directive for a more dynamic phase.

\footnotetext{
staem na načale kovrika, stopy vmeste. Soedinili ladoni pered soboj v namaste. Kosnulis' lbom končikov pal'cev, nastroilis' na praktiku. Vytjanuli ruki vverh, sdelali vdoh, naklon vniz, kosnulis' pal'cami ruk pola ...

stand-1PL-IND (NON-PAST)-IPFV on edge mat-GEN.SG, feet together. Join-1PL-

IND (PAST)-P F hand $_{-\mathrm{ACC} . \mathrm{PL}}$ front oneself in namaste. Touch-1PL-IND (PAST)PFV $_{\text {forehead }}$ INS.SG $_{\text {tip finger }}$-GEN.PL $_{\text {, tune-1PL-IND (PAST)-PFV }}$ on practiceACC.sG , stretch-1PL-IND (PAST)-PF hand -ACC.PL $_{\text {L }}$ up, do-1PL-IND (PAST)-PFV breath $_{-\mathrm{ACC} . \mathrm{SG}_{\mathrm{G}}}$, bend -ACC.SG $_{\text {A }}$ down, touch-1PL-IND (PAST)-PFV finger $_{-\mathrm{INS} . \mathrm{PL}}$ hand $_{- \text {GEN.PL }}$ floor $_{- \text {GEN.SG }} \ldots$

'(We) stand on the edge of the mat, feet together. (We) joined hands in front in namaste. (We) touched the fingertips with the forehead, (we) tuned into the practice. (We) stretched our hands up, breathed in, bent down, touched the floor with our fingers ...'
}

We consider the use of the construction in (15) as representative of the contexts in which instructions in the past indicative are most likely to occur in Russian.

\section{Conclusions}

The analysis which we have presented focuses on language-specific preferences and between-language differences in the selection of directives in two genetically related Slavic languages, which still remain under-studied, and in the discourse genre which is very rarely investigated. We have set out to examine authentic spoken utterances which occur in a very special context, whereby - as in Slobin's Frog Story experiment - many factors are equal in both languages. Specifically, our analysis has brought to the fore the differences in the preferred directive constructions used by Polish and Russian yoga teachers, whereby the contextual circumstances of the speaker-hearer interaction as well as the interactive behavioral effects of the directive constructions are equal in both languages, while the meanings conveyed by the constructions are comparable. 


\section{GÓRALCZYK AND ŁOZIŃSKA}

We have been able to establish that the two languages exhibit some striking similarities as out of a pool of (families of) constructions which are available for directive use in each of them, the two major morphosyntactic patterns which are conventionally selected in the studied discourse genre are the same, the imperative and the imperfective non-past indicative. The third construction that has been examined, i.e., the past indicative, is in the discourse genre under scrutiny only available to the speaker of Russian. Even though there is an analogous morphosyntactic pattern in Polish, it is never selected in the discourse of yoga. A range of other constructions have been shown to have a marginal or negligible share in the data that we have collected.

Given that the constructions employed as yoga instructions are generally weak directives, which can nonetheless vary slightly in their force impact, we have argued that the imperative and the imperfective non-past indicative patterns code relatively weaker illocutionary force impact in both languages, when compared to the past indicative. In our analysis, three major aspects of construal have been identified to contribute to the overall illocutionary force impact as: (i) the actuality or virtuality of the event presented in the utterance; (ii) the presence or absence of the Speaker in the onstage region; and (iii) the aspectual opposition between an ongoing and completed event.

Thus, we shall claim that the difference in the distribution patterns of yoga instructions in Russian and Polish can at least partially be explained as an effect of a greater diversity of the system of Russian directives, in which the speaker can make finer distinctions in force impact, while the speaker of Polish can make somewhat broader distinctions. In other words, the constructions in Russian enable the speaker to express change in the force impact in finergrained detail than in Polish.

Finally, we have related force impact in (generally weak) yoga instructions to aspects of construal which can be identified independently of the introspective judgments of the speakers of Polish and Russian.

\section{REFERENCES}

Achard, M. (1998). Representation of cognitive structures. syntax and semantics of French sentential complements. Berlin: Mouton de Gruyter.

Austin, J. L. (1962). How to do things with words: the William fames lectures delivered at Harvard University in 1955 (edited by J. O. Urmson). Oxford: Clarendon Press.

Bach, K. \& Harnish, R. M. (1979). Linguistic communication and speech acts. Cambridge, MA: MIT Press.

Belikov, V. I. (2001). Avtoritarnyj imperativ v russkom jazyke Russkij jazyk: istoričeskie sud'by i sovremennost'. Meždunarodnyj kongress rusistov-issledovatelej. Trudy i materialy. M.: Izd. MGU, p. 162.

Belošapkova, V. A. (1997). Sovremennyj russkij jazyk [Modern Russian language]. Moskva.

Biberauer, T., Holmberg, A., Roberts, I. \& Sheehan. M. (2010) Parametric variation: null subject in Minimalist theory. Cambridge: Cambridge University Press. 


\section{YOGA INSTRUCTIONS AS DIRECTIVE PEECH ACTS}

Croft, W. (1994). Speech act classification, language typology and cognition. In S. L. Tsohatzidis (ed.), Foundations of speech act theory: philosophical and linguistic perspectives (pp. 460-477). London: Routledge.

Dickey, S. (2020). Time out of tense: Russian aspect in the imperative. Fournal of Linguistics 56 (3), 541-576.

Grenoble, L. (1989). Tense, mood, aspect: the future in Russian. Russian Linguistics 13(2), 97-110.

Grenoble, L. A. (1995). The imperfective future tense in Russian. Word 46(2), 183-205.

Gusev, V. (2013). Tipologija imperativa. In Fazyki slavjanskix kul'tur. Moscow.

Kochańska, A. (2002). A cognitive grammar analysis of Polish nonpast perfectives and imperfectives: how virtual events differ from actual ones. In F. Brisard (ed.), Grounding: the epistemic footing of deixis and reference (pp. 349-390). Berlin and New York: Mouton de Gruyter.

Kochańska, A. (2011). Kilka uwag o gramatyce dyrektywnych aktów mowy w języku polskim [A few remarks on the grammar of directive speech acts in Polish]. In A. Kwiatkowska (ed.), Przestrzenie kognitywnych poszukiwań [Spaces of cognitive xxplorations] (pp. 177-194). Łódź: Wydawnictwo Uniwersytetu Łódzkiego.

Kochańska, A. (2015). Cognitive grammar, speech acts, and interpersonal dynamics: a study of two directive constructions in Polish. Cognitive Linguistics 26(1), 61-94.

Kochańska, A. (2018). The hurting and healing power of words (and grammatical constructions): a Cognitive Grammar study of the interactive and interpersonal effects of a directive construction in Polish. Fournal of Pragmatics 134, 1-14.

König, E. \& Siemund, P. (2007). Speech act distinctions in grammar. In T. Shopen (ed.), Language typology and syntactic description (pp. 276-324). Cambridge: Cambridge University Press.

Langacker, R. W. (1991). Foundations of cognitive grammar, Vol. 2: theoretical prerequisites. Stanford, CA: Stanford University Press.

Langacker, R. W. (1998). Indeterminacy in semantics and grammar. In J. L. Cifuentes Honrubia (ed.), Estudios de Lingüistica Cognitiva II: Universidad de Alicante, Departamento de Filología Espaňola, Lingüistica General y Teoría de la Literatura (pp. 649-672). Alicante.

Langacker, R. W. (1999). Virtual reality. Studies in the Linguistic Sciences 29, 77-103.

Langacker, R. W. (2004). Aspects of the grammar of finite clauses. In M. Achard \& S. Kemmer (eds), Language, culture, and mind (pp. 535-577). Stanford, CA: CSLI Publications.

Langacker, R. W. (2008). Cognitive Grammar: A Basic Introduction. New York: Oxford University Press.

Langacker, R. W. (2009). Investigations in Cognitive Grammar. Berlin and New York: Mouton de.

Levinson, S. C. (1983) Pragmatics. Cambridge: Cambridge University Press.

Mel'ničuk, O. S. (1966). Rozvitok strukturi slov'anskogo rečennja. Kiev: Naukova dumka.

Panther, K.-U. \& Thornburg, L. L. (1998). A cognitive approach to inferencing in conversation. Fournal of Pragmatics 30(6), 755-769.

Panther, K.-U. \& Thornburg, L. L. (1999). The potentiality for actuality metonymy in English and Hungarian. In K.-U. Panther \& G. Radden (eds), Metonymy in language and thought (pp. 333-357). Amsterdam and Philadelphia: John Benjamins.

Panther, K.-U. \& Thornburg, L. L. (2003). Metonymies as natural inference and activation schemas: the case of dependent clauses as independent speech acts. In K.-U. Panther \& L. L. Thornburg (eds), Metonymy and pragmatic inferencing (pp. 127-147). Amsterdam and Philadelphia: John Benjamins.

Pérez Hernandez, L. \& Ruiz de Mendoza, F. J. (2002). Grounding, semantic motivation, and conceptual interaction in indirect directive speech acts. Fournal of Pragmatics 34(3), 259-284.

Pérez Hernandez, L. \& Ruiz de Mendoza, F. J. (2011). A lexical-constructional model account of illocution. Vigo International Fournal of Applied Linguistics 8, 99-138.

Radden, G. (2014). Making sense of negated modals in English: with a glimpse at other Germanic languages. Review of Cognitive Linguistics 12(2), 471-491.

Radden, G. \& Dirven, R. (2007). Cognitive English grammar. Amsterdam and Philadelphia: John Benjamins. 


\section{GÓRALCZYK AND ŁOZIŃSKA}

Radden, G. \& Panther, K.-U. (2004). Introduction: reflections on motivation. In G. Radden \& K.-U. Panther (eds), Studies in linguistic motivation (Cognitive Linguistic Research 28) (pp.1-46). Berlin and New York: Mouton de Gruyter.

Recanati, F. (1987). Meaning and force. Cambridge: Cambridge University Press.

Ruiz de Mendoza, F. J. (2014). On the nature and scope of metonymy in linguistic description and explanation: towards settling some controversies. In J. Littlemore \& J. R. Taylor (eds), The Bloomsbury companion to cognitive linguistics (pp. 143-167). London: Bloomsbury.

Ruiz de Mendoza, F. J. \& Baicchi, A. (2007). Illocutionary constructions: cognitive motivation and linguistic realization. In I. Kecskes \& L. R. Horn (eds), Explorations in pragmatics: linguistic, cultural and intercultural aspects (pp. 95-128). Berlin: Mouton de Gruyter.

Searle, J. R. (1969). Speech acts: an essay in the philosophy of language. Cambridge: Cambridge University Press.

Searle, J. R. (1976). A classification of illocutionary acts. Language in Society 5(1), 1-23.

Siemund, P. (2018). Speech acts and clause types: English in a cross-linguistic context. Oxford: Oxford University Press.

Takahashi, H. (2012). A cognitive linguistic analysis of the English imperative with special reference to Fapanese imperatives. Amsterdam: Benjamins.

Thornburg, L. L. \& Panther, K.-U. (1997). Speech act metonymies. In W.-A. Lierbert, G. Redeker \& L. R. Waugh (eds), Discourse and perspective in cognitive linguistics (pp. 205-219). Amsterdam: John Benjamins.

Xrakovskij, V. S. \& Volodin, A. P. (1986/2001). Semantika i tipologija imperativa. Russkij imperativ. URSS.

\section{Appendix}

Selected yoga tutorials in Polish:

$<$ https://www.youtube.com/watch?v=D6VP1Sx_hOE $>$

$<$ https://www.youtube.com/watch?v=dciAcZBYN90 $>$

$<$ https://www.youtube.com/watch?v=JFHSz62mnv0>

$<$ https://www.youtube.com/channel/UCBakkxKoa1gHXTT'TxfO-QVQ>

$<$ https://www.youtube.com/watch?v=ALI-Id0odWE $>$

Selected yoga tutorials in Russian:

$<$ https://www.youtube.com/watch?v=jvZb7NA10Po $>$

$<$ https://www.youtube.com/watch?v=E5i4rDc_GA8>

$<$ https://www.youtube.com/watch?v=tV3XpInpgGY\&list=PLY43o

v4aunB7vbskqUFtt0r0z9VhYKCFf $>$

$<$ https://www.youtube.com/watch?v=-sfAlSIF7Xk>

$<$ https://www.youtube.com/watch?v=y2uvUiG9eIo> 